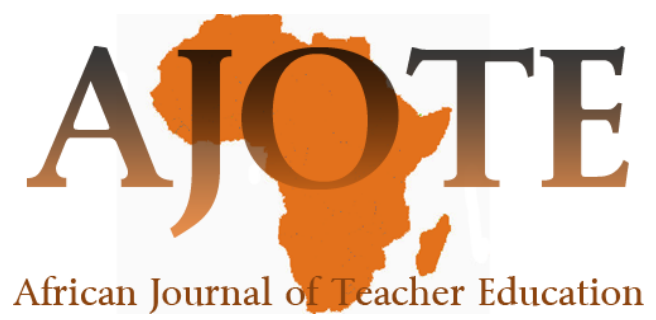

\title{
THE EFFECT OF TIMING OF TEACHING RELEVANT MATHEMATICS PRINCIPLES ON ACHIEVEMENT IN CHEMISTRY
}

\author{
Franca Offiah \\ Nnamdi Azikiwe University, Nigeria \\ Naomi Samuel \\ Nnamdi Azikiwe University High School, Nigeria
}

\begin{abstract}
This study is on the influence of a prior knowledge of mathematics principles on achievement in chemistry. The researcher investigated whether or not students' achievement in chemistry could be improved by teaching them selected mathematical principles before teaching chemistry or teaching them selected mathematical principles simultaneously with chemistry. The study was carried out in Anambra State Nigeria. The design is quasi-experimental involving 300 secondary 2 students from six secondary schools distributed into three groups. Group one was taught mathematics before chemistry, group two, was taught mathematics simultaneously with chemistry, while group three received no special mathematics lesson. The groups were pre-tested with an instrument comprised of 50 multiple choice questions in chemistry and post-tested with a reshuffled edition of the pre-test after experiment. The researchers used ANCOVA to analyze the results, which revealed that the students taught mathematics before chemistry outperformed other groups.
\end{abstract}




\section{Introduction}

With the advancement of science and technology, the focus of chemical research has changed thereby affecting topics covered in modern chemistry courses. The interaction between different science subjects has increased. The need of knowing related subjects is enhanced due to the many applications of chemistry. Chemistry is sister to all the natural science subjects and is also an important subject in medical and engineering sciences. Due to its widespread applications and complexity of problems, it involves mathematics as a main partner in achieving its goals. Mathematics is used widely in chemistry as well as other sciences. Mathematical calculations are absolutely necessary to explore important concepts in chemistry. Without some basic mathematical skills, these calculations and therefore chemistry will be extremely difficult. Taking mathematics as a tool, many complicated problems are solved and the results are obtained in a simple but logical way which otherwise would prove very difficult.

According to Etukodo and Nnaobi (2002), the place of mathematical skill in teaching chemistry for sustainable development should be emphasized as the lack of requisite mathematical skills makes it impossible to produce chemistry graduates from diverse educational programs that can fit effectively into the world of work or accurately apply what they have learned to real life problems.

\section{Statement of Problem}

Inadequate mathematics education is one of the problems identified that militates against students' progress in chemistry (Webb 1973, Ali 1983, Akpan 1988). Some mathematical tasks and principles are frequently taught in secondary school chemistry. Knowledge of such tasks and principles is essential for understanding secondary school chemistry. The problem addressed in this study is the question of when is it most appropriate to teach a student the mathematical principles essential for understanding chemistry.

\section{Purpose of Study}

The researchers want to determine if students' achievement in chemistry can be improved by teaching them selected mathematical principles (SMPs) before chemistry is taught or by teaching them SMPs simultaneously with chemistry.

\section{Significance of Study}

This study's findings will aid the curriculum planning experts in determining the stage at which relevant mathematical concepts important for particular topics in chemistry should be studied. It will motivate mathematics and chemistry teachers to engage in team teaching.

\section{Scope of Study}

Chemistry requires a number of mathematics principles and concepts for easy comprehension. In this work, the following mathematical concepts were considered:

Significant digits

Scientific notations

Unit analysis

Structured problem solving approach.

Students were taught the above mathematical concepts under the following mathematics topics: Significant figures

AJOTE Vol. 2. No. 1 (2012) 
Simple equations

Statistical treatment of data

Change of subject formula

Mensuration (Measurement)

The chemistry topics covered in this study include:

Electrolysis

Energy and Chemical Reaction

Gas laws.

\section{Research Questions}

In order to carry out an effective study, the researchers formulated the following questions:

- $\quad$ To what extent do students who receive prior lessons on SMPs before receiving chemistry lessons and those who receive lessons on SMPs and chemistry simultaneously differ in their achievement in chemistry?

- $\quad$ To what extent do students who were taught SMPs and chemistry simultaneously and those who received lessons in chemistry only differ in their achievement in chemistry?

- $\quad$ To what extent do students who received lessons on SMPs prior to lessons in chemistry and those who received lessons in chemistry only differ in their achievement in chemistry?

\section{Hypotheses}

The following hypotheses were formulated at 0.05 level of significance:

- $\quad$ There is no significant difference in the chemistry achievement level between students who received prior lessons on SMPs before chemistry lessons and those who received lessons on SMPs and chemistry simultaneously using their post-test scores.

- $\quad$ There is no significant difference in the chemistry achievement level between students who received only chemistry lessons and those who received SMPs and chemistry simultaneously using their post-tests.

\section{Research Design}

The design was quasi-experimental and used intact classes of students. Pre-tests and post-tests were incorporated in the design. There were two experimental groups and one control group.

Group I: $\quad$ Students who were taught SMPs before they were taught chemistry.

Group II: $\quad$ Students who were taught SMPs and chemistry simultaneously.

Group III: $\quad$ Students who were taught only chemistry with no special mathematical principles.

\section{Area of Study}

This study was conducted in the Awka Education Zone of Anambra State, Nigeria which includes the following five local government areas:
- $\quad$ Awka South Local Government Area
- $\quad$ Awka North Local Government Area
- $\quad$ Anaocha Local Government Area
- $\quad$ Dunukofia Local Government Area

AJOTE Vol. 2. No. 1 (2012) 
- $\quad$ Njikoka Local Government Area.

All five Local Government Areas participated in the study.

\section{Population}

The study population encompassed all senior secondary, form 2 (SSII) students studying chemistry among other sciences in all state government-owned secondary schools in Awka Education Zone.

\section{Sample and Sampling Technique}

This study involved 300 SSII students from six secondary schools in Awka Education Zone. Intact classes of 50 students each were selected. The selection of schools and classes used was by random sampling with replacement.

\section{Instrument Used for Data Collection}

The instrument utilized for data collection was the Chemistry Achievement Test (CAT). All questions in the CAT were based on chemistry concepts and principles taught to the SSII students. The CAT comprised 50 objective test items. The multiple-choice questions were designed for validity and clarity of expressions. Each question had plausible destructors. A minimum of four options were used for all questions because the larger the number of plausible destructors the greater the reliability of the test items. Listed below are the item specifications for the CAT.

\section{Table 1}

Item Specifications for Chemistry Achievement Test

\begin{tabular}{|l|l|l|l|l|l|l|l|}
\hline Course & $\begin{array}{l}\text { Knowled } \\
\text { ge }\end{array}$ & $\begin{array}{l}\text { Compre } \\
\text { hension }\end{array}$ & Application & Analysis & Synthesis & $\begin{array}{l}\text { Evaluati } \\
\text { on }\end{array}$ & Total \\
\hline $\begin{array}{l}\text { Electrolysis } \\
20 \%\end{array}$ & $1(2 \%)$ & $2(4 \%)$ & $2(4 \%)$ & $2(4 \%)$ & $2(4 \%)$ & $1(2 \%)$ & $10(20 \%)$ \\
\hline $\begin{array}{l}\text { Energy } \\
\text { Chemical } \\
\text { Reaction } 58 \%\end{array}$ & $3(6 \%)$ & $2(8 \%)$ & $6(12 \%)$ & $6(12 \%)$ & $5(10 \%)$ & $5(10 \%)$ & $29(58 \%)$ \\
\hline Gas laws 22\% & $2(4 \%)$ & $2(4 \%)$ & $2(4 \%)$ & $2(4 \%)$ & $2(4 \%)$ & $1(2 \%)$ & $11(22 \%)$ \\
\hline Total 100\% & $\mathbf{6 ( 1 2 \% )}$ & $\mathbf{8 ( 1 6 \% )}$ & $\mathbf{1 0}(\mathbf{1 0 \%})$ & $\mathbf{1 0}(\mathbf{2 0 \% )}$ & $\mathbf{9 ( 1 8 \% )}$ & $\mathbf{7 ( 1 4 \% )}$ & $\mathbf{5 0 ( 1 0 0 \% )}$ \\
\hline
\end{tabular}

A raw possible score of 100 (2 points per item) was allotted to the objective test. The validity of the CAT was further ensured by subjecting the CAT to a panel of experts for a critique of content coverage, clarity, and level appropriateness.

\section{Treatment Procedure}

The three groups used in the study were found to be academically equivalent before commencement of the treatments. Two major treatments were implemented. The first was the mathematics teaching referred to as the SMPs that included significant digits, scientific notation, unit analysis, equation transposing, and a structured problem solving approach. These concepts were taught under the following topics: significant figures, simple equations, statistical treatment of data, change of subject formula, and mensuration (measurement). The second teaching treatment was chemistry teaching. The following topics, part of the SSII curriculum for senior

AJOTE Vol. 2. No. 1 (2012) 
school chemistry, were covered: electrolysis, energy and chemical reaction, and calculation on gas laws. The three groups were all given a pre-test of the CAT before commencing the experiment. The study lasted for six weeks.

Group I: During the first two weeks this group was taught SMPs by mathematics teachers using two double periods per week (i.e. 4 periods per week) totaling eight periods of 40 minutes each for these two weeks. From the third to the sixth weeks, chemistry was taught to the students by their chemistry teacher using two double periods per week for a total of 16 periods of 40 minutes each for these four weeks.

Group II: This group was also taught SMPs by their mathematics teacher. However, the mathematics lesson preceded the chemistry lesson each day. At the end of the mathematics lesson, the chemistry teacher started the chemistry lesson. One mathematics period was taught per week for the first four weeks of the study and two periods per week in the last two weeks (fifth and the sixth weeks). Chemistry was taught from the beginning of the first week to the last week of the study. Thus chemistry was taught along side mathematics.

A total of eight periods of mathematics and 16 periods of chemistry were taught to this group as with group I. The difference for Group II was that three periods of chemistry were taught per week for the first four weeks; then for the last two weeks two periods of chemistry were taught per week.

Group III: This was the control group. They were not taught SMPs. From the third week, this group was taught chemistry at the rate of four periods per week. At the end of six weeks, all members of the three groups were given three days for review. The post-test was then administered to each group.

\section{Data Analysis}

Table 2

Groups I and II Pre and Post-Test Mean Scores

\begin{tabular}{|l|l|l|l|}
\hline Source of variation & Pre-test mean & Post-test mean & Mean gain \\
\hline Group I $(\mathrm{N}=100)$ & 10.22 & 66.52 & 56.30 \\
\hline Group II $(\mathrm{N}=100)$ & 11.32 & 52.36 & 41.04 \\
\hline
\end{tabular}

Table 2 lists pre and Post-test mean score for Group I and Group II. Group I received lessons on SMPs before they received chemistry lessons. Group II received lessons on SMPs and chemistry lessons simultaneously.

Table 3

Groups II and III Pre and Post-Test Mean Scores

\begin{tabular}{|l|l|l|l|}
\hline Source of variation & Pre-test mean & Post-test mean & Mean gain \\
\hline Group II (N=100) & 11.32 & 52.36 & 41.04 \\
\hline Group III (N=100) & 11.49 & 43.50 & 32.01 \\
\hline
\end{tabular}

Table 3 lists pre and post-test mean scores of Group II students who received lessons on SMPs and chemistry lessons simultaneously and Group III pre and post-test mean scores who received only chemistry lessons.

\section{Table 4}

Groups I and III Pre and Post-Test Mean Scores

AJOTE Vol. 2. No. 1 (2012) 


\begin{tabular}{|l|l|l|l|}
\hline Source of variation & Pre-test mean & Post-test mean & Mean gain \\
\hline Group I (N=100) & 10.22 & 66.52 & 56.30 \\
\hline Group III (N=100) & 11.49 & 43.50 & 32.01 \\
\hline
\end{tabular}

Table 4 lists pre and post-test mean scores of Group 1 students who received lessons on SMPs prior to chemistry lessons and Group III pre and post-test mean scores who received only chemistry lessons.

ANCOVA comparison was used on the post-test mean scores of all three groups. This was used to test hypotheses 1 and 2.

\section{Table 5}

ANCOVA of the Mean Scores for All Three Groups' CAT Post-tests

\begin{tabular}{|l|l|l|l|l|l|l|}
\hline $\begin{array}{l}\text { Source of } \\
\text { variation }\end{array}$ & $\begin{array}{l}\text { sum of } \\
\text { squares }\end{array}$ & $\mathbf{d f}$ & $\begin{array}{l}\text { Mean } \\
\text { square }\end{array}$ & Cal. F & Crit. F & P $>\mathbf{0 . 5}$ \\
\hline $\begin{array}{l}\text { Corrected } \\
\text { models }\end{array}$ & 38368.90 & 6 & 6394.82 & & & \\
\hline Intercept & 170985.53 & 1 & 9714.75 & & & \\
\hline $\begin{array}{l}\text { Experimental } \\
\text { group }\end{array}$ & 29397.37 & 2 & 14698.68 & 207.93 & 3.00 & 0.05 \\
\hline Error Residual & 20712.29 & 293 & 70.69 & & & \\
\hline Total & $\mathbf{9 3 7 9 9 0 . 0 0}$ & $\mathbf{3 0 0}$ & & & & \\
\hline
\end{tabular}

Table 5 lists the ANCOVA of the mean scores from the CAT post-test for all students in chemistry after receiving the treatments as previously described. It indicates that at 0.05 level of significance, $2 \mathrm{df}$ numerator and $299 \mathrm{df}$ denominator, the calculated F, 207.93 is greater than the critical F, 3.00. The researchers then concluded that there is a significant difference in the achievement level among chemistry students after receiving treatment in their various groups.

\section{Summary of Findings}

The analysis produced the following major findings:

- $\quad$ Chemistry students who were taught mathematical principles prior to chemistry lessons performed better than those who received SMPs and chemistry lessons simultaneously.

- $\quad$ Students who received lessons on SMPs and chemistry simultaneously performed better than those who were taught only chemistry.

- $\quad$ Students who received lessons on SMPs prior to chemistry lessons performed better than those who were taught only chemistry.

\section{Discussion and Conclusion}

The study has revealed that giving students prior lessons on SMPs before they are taught chemistry has a significant effect on achievement in chemistry. Looking at the achievement of the two experimental groups, it is clear that the group which was taught SMPs for the six weeks prior to when chemistry was taught performed better than the group taught SMPs and chemistry at the same time. The researchers concluded that the timing of teaching the SMPs was the main factor contributing to the variation in achievement. The result of this investigation shows that teaching mathematics before chemistry ensures higher student achievement than teaching the 
essential mathematics and chemistry simultaneously. Thus for maximum student performance and academic success in chemistry at senior secondary school, essential mathematic principles should be a prerequisite for students who wish to study chemistry.

\section{Recommendations}

In the senior secondary school system, teachers in the science and mathematics departments should work as a team. The teachers should certify that all required mathematic principles essential for chemistry, physics, etc., are taught in senior secondary, form 1 and ensure that students master these concepts before they are begin chemistry coursework. Finally, the chemistry teacher should ensure that all essential mathematic principles for chemistry taught by the mathematics teacher are reviewed with students by the chemistry teacher before they begin teaching chemistry.

\section{REFERENCES}

Ali, A. (1983). The performance of Nigeria secondary school ordinary level science students' mathematical task essential for secondary school science. Journal of Science Teachers Association of Nigeria, 22(2), 60-62.

Akpan, A.A. (1988). Role of mathematics in science education circular. Journal of CITADEL, 2(5), 121-123.

Etukodo, U.E., \& Nnaobi, A.F. (2002). Chemistry for sustainable development. $43^{\text {rd }}$ Annual Conference Proceeding of Science Teachers Association of Nigeria, 254-258.

Orton, T., \& Roper, T. (2000). Science/mathematics a relationship in need of counseling? Studies in Science Education, 35, 123-154.

Webb, N.G.G. (1973). Developing good relationship between mathematics and science. School Science Review, 54 (188), 441-449. 